\title{
Penggunaan Indeks Google Trend Dalam Peramalan Jumlah Pengunjung Taman Rekreasi Selecta Tahun 2020
}

\author{
(The Use of Google Trend Index for Predicting Selecta Visitors in 2020) \\ Novia Permatasari \\ Badan Pusat Statistik Jakarta Timur \\ E-mail: novia.permatasari@bps.go.id
}

\begin{abstract}
ABSTRAK
Kota Batu merupakan salah satu daerah potensi pariwisata di Indonesia, dengan salah satu tujuan pariwisata andalan adalah Taman Rekreasi Selecta. Sejak tahun 2016 hingga 2019, Taman Rekreasi Selecta secara konsisten menjadi tempat wisata dengan jumlah pengunjung terbanyak di Kota Batu. Publikasi data kunjungan wisatawan yang hanya dilakukan sekali dalam satu tahun menunjukkan adanya selang waktu antara pengumpulan dan publikasi data, sehingga pemanfaatan data kunjungan wisatawan tersebut kurang maksimal. Permasalahan tersebut dapat diatasi dengan memanfaatkan realtima data, yaitu big data. Pada penelitian ini, peneliti akan melakukan nowcasting jumlah pengunjung Taman Rekreasi Selecta pada tahun 2020, serta menggunakan Indeks Google Trend (IGT) yang diharapkan mampu meningkatkan akurasi hasil prediksi. Metode peramalan data runtun waktu yang digunakan adalah SARIMA dan SARIMAX dengan IGT sebagai variabel penjelas. Dibandingkan dengan model SARIMA, metode SARIMAX dengan IGT mampu menurunkan nilai $M A E$ data out-sample hingga $32 \%$ dan MAPE sebesar 28\%. Perbandingan kedua metode juga menunjukkan bahwa hasil peramalan menggunakan SARIMAX dengan IGT lebih mampu menangkap volatilitas data runtun waktu dari pada model SARIMA. Hasil peramalan jumlah pengunjung Selecta tahun 2020 menunjukkan sempat terjadinya penurunan jumlah pengunjung akibat pandemi covid-19 dan kembali naik diakhir tahun 2020.
\end{abstract}

Kata kunci: Nowcasting, SARIMA, SARIMAX, Indeks Google Trend

\begin{abstract}
Batu City is one of the potential tourism areas in Indonesia, with one of the mainstay destinations is Selecta. Since 2016 to 2019, Selecta has consistently been a tourist spot with the highest number of visitors in Batu City. Publication of tourist visit data which is only carried out once a year shows that there is a time lapse between data collection and publication, thus making the utilization of tourist visit data less than optimal. These problems can be overcome by utilizing real-time data, namely big data. In this study, researchers will nowcast the number of Selecta visitors in 2020, and use the Google Trend Index (IGT) which is expected to increase the accuracy of prediction. The time series forecasting method used is SARIMA and SARIMAX by including IGT as an explanatory variable. Compared to SARIMA model, SARIMAX with IGT was able to decrease the MAE of out-sample up to $32 \%$ and MAPE up to $28 \%$. The comparation of both models shows that SARIMAX with IGT forecasting are better to capture the volatility of time series data than SARIMA model. The result of Selecta visitors forecasting in 2020 showed that that there had been a decline in the number of visitors due to the covid19 pandemic and returned to increase in the end of 2020.
\end{abstract}

Keywords: Nowcasting, SARIMA, SARIMAX, Google Trend Index

\section{PENDAHULUAN}

Kota Batu merupakan salah satu daerah dengan potensi pariwisata di Indonesia. Kota Batu memiliki panorama yang indah, suhu udara yang sejuk dan tidak lembab, sehingga menjadikannya tujuan wisata andalan di Jawa Timur (Hanas \& Sasmita, 2014). Hal tersebut semakin diperkuat dengan dicanangkannya Kota Batu sebagai Kota Wisata pada tahun 2010. Pada tahun 2019, telah terdapat 30 objek wisata dan wisata oleh-oleh dengan total pengunjung mencapai lebih dari 6 juta jiwa (BPS Kota Batu, 2020). Beberapa objek wisata yang terkenal antara lain: Jatim Part I, Jatim Park II, Jatim Park III, Museum Angkut, Selecta, dan Alun-Alun Kota Batu.

Salah satu tujuan pariwisata andalan di Kota Batu adalah Taman Rekreasi Selecta, yang didirikan sejak tahun 1928 (Hanas \& Sasmita, 2014). Sejak tahun 2016 hingga 2019, Taman Rekreasi Selecta secara konsisten menjadi tempat wisata dengan jumlah pengunjung terbanyak di Kota Batu. Pada tahun 2019, total pengunjung Selecta mencapai 1.394.270 jiwa. Angka ini jauh melebihi tempat rekreasi lainnya, seperti Jatim Park III dengan 803.214 pengunjung, Jatim Park II dengan 757.928 pengunjung, dan Museum Angkut dengan 453.873 pengunjung. 
Jumlah wisatawan yang semakin meningkat menjadi tolak ukur keberhasilan sekaligus tantangan bagi pengelola objek pariwisata. Pengelola objek wisata harus memperhatikan kapasitas kunjungan serta jumlah akomodasi yang harus disediakan guna menciptakan kenyamanan bagi para wisatawan. Selain itu, pemerintah dan sektor swasta diharapkan mampu memanfaatkan kunjungan wisatawan guna mendapatkan manfaat di sektor-sektor lainnya, seperti: jasa, transportasi, serta penyediaan makanan dan minuman.

Data kunjungan wisatawan merupakan salah satu publikasi tahunan Badan Pusat Statistik (BPS). Publikasi yang hanya dilakukan sekali dalam satu tahun menunjukkan adanya selang waktu antara pengumpulan dan publikasi data. Adanya selang waktu tersebut menjadikan pemanfaatan data kunjungan wisatawan kurang maksimal. Permasalahan selang waktu tersebut dapat diatasi menggunakan metode peramalan untuk mendapatkan pendugaan saat ini.

Pada era teknologi saat ini, big data memiliki potensi yang begitu besar sebagai sumber data baru. Salah satu keunggulan dari big data adalah pengumpulan yang dapat dilakukan secara realtime sehingga dapat digunakan untuk memprediksi kondisi saat ini, atau biasa disebut dengan nowcasting. Nowcasting merupakan bentuk spesial dari forecasting atau peramalan yang berhubungan dengan informasi-informasi yang terjadi saat ini atau mendekati saat ini (Baribura, Giannone, \& Reichlin, 2010).

Penggunaan big data sebagai statistik resmi dapat dilihat dari beberapa publikasi dari Badan Pusat Statistik, diantaranya mengenai dampak pandemi covid-19 di tahun 2020 (Badan Pusat Statistik, 2020) dan masa adaptasi kebiasaan baru (Badan Pusat Statistik, 2020). Big data juga dapat digunakan bersama dengan statistik resmi untuk menghasilkan hasil estimasi dan analisa yang lebih baik. Beberapa penelitian yang telah dilakukan, diantaranya: estimasi nilai GDP dimasa pandemi menggunakan Google Mobility (Anugrah Putra \& Arini), serta penggunaan Google Trend guna melakukan nowcasting pengeluaran perkapita (Fasulo, Guandalini, \& Terribili, 2017), Tingkat Pengangguran Terbuka (TPT) (Akbar \& Kurniawan, 2020), dan kedatangan wisatawan asing (Antolini \& Grassini, 2018). Keempat penelitian menunjukkan bahwa penggunaan variabel tambahan dari big data mampu memperbaiki model yang didapatkan.

Peramalan jumlah pengunjung tempat wisata di Kota Batu telah dilakukan oleh Setyobudi (2017) guna memprediksi jumlah pengunjung Selecta di tahun 2017 dengan metode ARIMA. Penelitian tersebut hanya menggunakan data runtun waktu jumlah pengunjung tahun 2010 - 2016 tanpa adanya informasi tambahan. Maka dari itu, penelitian ini bertujuan untuk melihat pengaruh peggunaan Indeks Google Trend (IGT) sebagai variabel penjelas pada model prediksi, serta melakukan prediksi jumlah pengunjung Selecta untuk tahun 2020.

\section{METODE}

\section{Pra-Proses Data}

Sebelum masuk dalam proses prediksi, akan dilakukan pra-proses data dengan imputasi data yang tidak lengkap. Metode imputasi yang digunakan adalah imputasi dengan dekomposisi seasonal - metode Kalman Smoothing. Kedua metode tersebut merupakan metode dengan kemungkinan hasil terbaik diantara metodemetode imputasi runtun waktu lainnya (Moritz \& Bartz-Beielstein, 2017). Metode imputasi dekomposisi seasonal - metode Kalman Smoothing dilakukan dalam dua tahapan, yaitu menghilangkan efek seasonal pada data dan dilanjutkan dengan proses imputasi dengan metode Kalman Smoothing.

\section{SARIMA dan SARIMAX}

Metode peramalan data runtun waktu yang digunakan adalah Seasonal Autoregressive Integrated Moving Average (SARIMA). Model SARIMA merupakan pengembangan dari model ARIMA yang digunakan untuk data runtun waktu musiman, yaitu data yang cenderung mengulangi suatu pola dalam musim tertentu. Model SARIMA atau ARIMA (p, d, q)(P, Q, S)S secara umum dapat ditulis sebagai berikut (Fransiska, Novianti, \& Agustina, 2019):

$$
\phi(B) \Phi_{P}\left(B^{S}\right)(1-B)^{d}\left(1-B^{S}\right)^{D} y_{t}=\theta(B) \Theta_{Q}\left(B^{S}\right) \varepsilon_{t}
$$

dimana::

$\begin{array}{ll}\phi(B) & : \text { AR non seasonal } \\ \Phi_{P}\left(B^{S}\right) & : \text { AR seasonal } \\ (1-B)^{d} & : \text { differencing non seasonal } \\ \left(1-B^{S}\right)^{D} & : \text { differencing seasonal } \\ \theta(B) & : \text { MA non seasonal } \\ \Theta_{Q}\left(B^{S}\right) & : \text { MA seasonal }\end{array}$


Peneliti juga akan menggunakan metode SARIMAX, yaitu modifikasi dari model SARIMA dengan menambah beberapa variabel yang dianggap memiliki pengaruh yang signifikan terhadap data penelitian. Model SARIMAX merupakan model regresi dengan error SARIMA, yang dapat ditulis sebagai berikut (Arunraj, Ahrens, \& Fernandes, 2016):

$$
\begin{aligned}
& y_{t}=\beta_{t} x_{t}+z_{t} \\
& \phi(B) \Phi_{P}\left(B^{S}\right)(1-B)^{d}\left(1-B^{S}\right)^{D} z_{t}=\theta(B) \Theta_{Q}\left(B^{S}\right) \varepsilon_{t}
\end{aligned}
$$

Sebelum dilakukan proses modelling runtun waktu, peneliti mengidentifikasi kestasioneran data. Untuk mengetahui kestasioneran data dalam varians, peneliti melihat nilai lambda pada transformasi Box-Cox. Proses pencarian nilai lambda maksimum, serta identifikasi model SARIMA dilakukan menggunakan function auto.arima() pada R. Model terbaik yang dihasilkan merupakan model dengan nilai Akaike Information Criterion (AIC), corrected Akaike Information Criterion (AICc), dan Bayesian Information Criterion (BIC) terendah. Proses pembentukan model SARIMA dan SARIMAX menggunakan function Arima() pada R.

Setelah didapatkan model runtun waktu terbaik, dilakukan proses pemeriksaan diagnostik guna melihat apakah model yang dihasilkan telah sesuai atau tidak. Pemeriksaan diagnostik dilakukan dengan memeriksa apakah error bersifat white noise dengan Uji Ljung-Box dan normalitas residual dengan Uji Kolmogorov Smirnov.

\section{Evaluasi Model}

Pada proses pembentukan model prediksi, peneliti membagi data menjadi in-sample dan out-sample. Data in-sample digunakan untuk membangun model peramalan, sedangkan data out-sample digunakan untuk mengevaluasi hasil peramalan (Eurostat, 2015). Dua indikator yang dapat digunakan untuk mengukur kebaikan model adalah Mean Absolute Error (MAE) dan Mean Absolute Percentage Error (MAPE) (Antolini \& Grassini, 2018), dengan rumus sebagai berikut:

$$
\begin{aligned}
& M A E=\frac{\sum_{t}\left|y_{t}-\hat{y}_{t}\right|}{n} \ldots \ldots \ldots \ldots . . . . . . \\
& M A P E=100 \% \frac{\sum_{t} y_{t}-\hat{y}_{t}}{n} .
\end{aligned}
$$

\section{Data dan Sumber Data}

Data yang digunakan adalah data jumlah pengunjung bulanan Taman Rekreasi Selecta yang didapatkan dari hasil penelitian sebelumnya (Setyobudi, 2017) untuk tahun 2012 s.d. 2016 dan data publikasi BPS untuk tahun 2018-2019. Untuk tahun 2017, data hasil publikasi BPS merupakan data agregasi tahunan, sehingga dilakukan imputasi data. Variabel penjelas yang digunakan adalah Indeks Google Trends yang diakses melalui link https://trends.google.co.id/trends/?geo=ID pada tanggal 13 Januari 2021 dengan memasukkan kata kunci "Selecta". Nilai IGT menunjukkan seberapa banyak kata kunci tersebut dicari pada Google.

\section{HASIL DAN PEMBAHASAN}

Data yang digunakan pada penelitian ini adalah data jumlah pengunjung Taman Wisata Selecta pada Januari 2012 s.d. Desember 2019, serta Indeks Google Trend pada Januari 2012 s.d. Desember 2020. Perkembangan jumlah pengunjung dan IGT berdasarkan waktu hingga tahun 2019 dapat dilihat pada Gambar 1. Terlihat bahwa kedua variabel memiliki pola yang sama. Nilai korelasi sebesar 0,859 menunjukkan bahwa kedua variabel memiliki korelasi kuat.

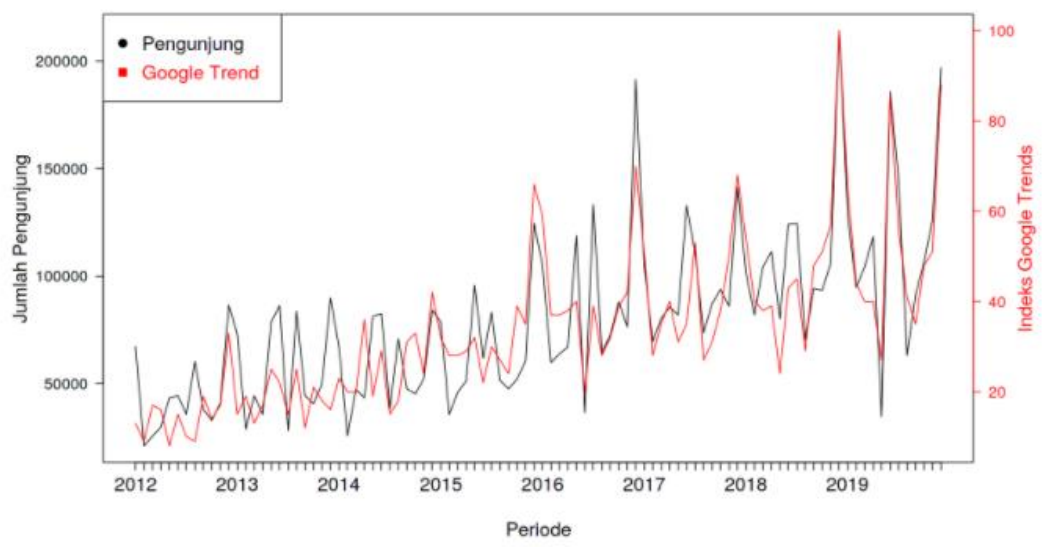

Gambar 1. Jumlah Pengunjung Selecta dan Indeks Google Trend Periode 2012 - 2019. 
Berdasarkan transformasi Box-Cox, didapatkan nilai lamda sebesar 0,177, dengan model SARIMA yang didapatkan adalah ARIMA(0,1,2)(1,0,0)[12]. Koefisien model SARIMA yang didapatkan adalah sebagai berikut:

Tabel 1. Koefisien model SARIMA.

\begin{tabular}{lll}
\hline Model & Parameter & Estimates \\
\hline & MA(1) & -1.0954 \\
ARIMA $(0,1,2)(1,0,0)[12]$ & $\operatorname{MA}(2)$ & 0.2275 \\
& $\operatorname{SAR}(1)$ & 0.7238 \\
\hline
\end{tabular}

Kemudian, peneliti memasukkan variabel penjelas IGT dalam model, sehingga didapatkan koefisien model sebagai berikut:

Tabel 2. Koefisien model SARIMAX.

\begin{tabular}{ccc}
\hline Model & Parameter & Estimates \\
\hline & MA(1) & $-1,1716$ \\
ARIMAX $(0,1,2)(1,0,0)[12]$ & $\operatorname{MA}(2)$ & 0.3183 \\
& SAR(1) & 0.6396 \\
& IGT & 0.0728 \\
\hline
\end{tabular}

Setelah mendapatkan model terbaik untuk keduanya, dilakukan pemeriksaan diagnostik guna mengetahui apakah kedua model telah layak atau tidak. Berdasarkan hasil uji diagnostik pada Tabel 3, diketahui bahwa kedua model telah layak, karena telah memenuhi asumsi error white noise dan residual yang berdistribusi normal.

Tabel 3. Hasil pengujian diagnostik model SARIMA dan SARIMAX.

\begin{tabular}{clcl}
\hline Model & Pengujian Diagnostik & p-value & \multicolumn{1}{c}{ Keputusan } \\
\hline \multirow{2}{*}{ SARIMA } & Uji Ljung Box & 0.9525 & Error bersifat white-noise \\
& Uji Kolmogorov Smirnov & 0.0607 & Residual berdistribusi normal \\
& Uji Ljung Box & 0.9848 & Error bersifat white-noise \\
& Uji Kolmogorov Smirnov & 0.161 & Residual berdistribusi normal \\
\hline
\end{tabular}

Tabel 4 menunjukkan perbandingan nilai MAE dan MAPE data in-sample dan out-sample dari kedua model. Nilai MAE dan MAPE pada model dengan tambahan indeks Google Trend lebih kecil dari model tanpa menggunakan IGT. Hal ini menunjukkan bahwa model SARIMAX mampu memprediksi dengan lebih baik dari model SARIMA tanpa variabel IGT. Tidak adanya perbedaan signifikan pada nilai MAE dan MAPE untuk data in-sampel dan out-sample menunjukkan bahwa model yang dihasilkan tidak overfit. Hal ini menunjukkan bahwa model tidak hanya mampu memprediksi data in-sample dengan baik, melainkan juga pada data outsample.

Tabel 4. Hasil evaluasi model SARIMA dan SARIMAX.

\begin{tabular}{|c|c|c|c|}
\hline Model & Data & MAE & MAPE \\
\hline \multirow{2}{*}{ SARIMA } & In-sample & 13758.1628 & 19,7734 \\
\hline & Out-sample & 18962.4721 & 17,6283 \\
\hline \multirow{2}{*}{ SARIMAX } & In-sample & 13078.1884 & 19,0030 \\
\hline & Out-sample & 12767.7615 & 12,6909 \\
\hline
\end{tabular}


Berikut adalah hasil prediksi pada data out-sample. Berdasarkan data tersebut, terlihat bahwa pola hasil peramalan kedua metode cenderung mengikuti pola data sebenarnya. Model SARIMAX dengan variabel IGT menunjukan hasil yang lebih baik dimana mampu menangkap volatilitas data daripada model SARIMA. Hasil ini sejalan dengan nilai MAPE dan MAE yang telah dijelaskan sebelumnya.
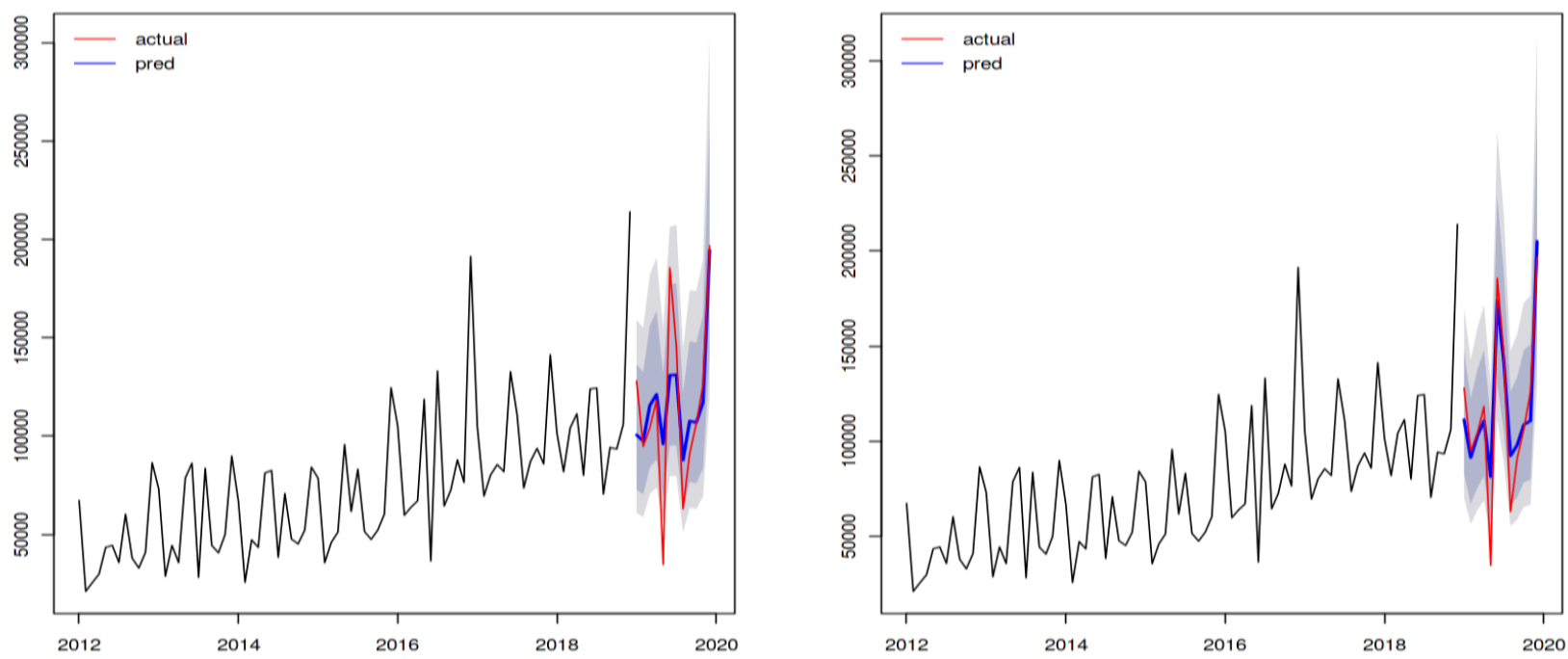

Gambar 2. Perbandingan jumlah pengunjung tahun 2019 dan hasil peramalan menggunakan model SARIMA (kiri) dan SARIMAX (kanan).

Berikut adalah hasil peramalan pengunjung Selecta pada tahun 2020. Jumlah pengunjung pada Bulan Maret sampai dengan Juli dikosongkan mengingat kebijakan PSBB yang mengharuskan berbagai tempat wisata menutup layanannya. Dibandingkan dengan bulan Januari dan Februari, terlihat bahwa terjadi penurunan jumlah pengunjung yang cukup tajam pada pertengahan hingga akhir tahun 2020. Hal ini dikarenakan kondisi pandemi yang menurunkan minat seseorang untuk berkunjung ke tempat wisata.

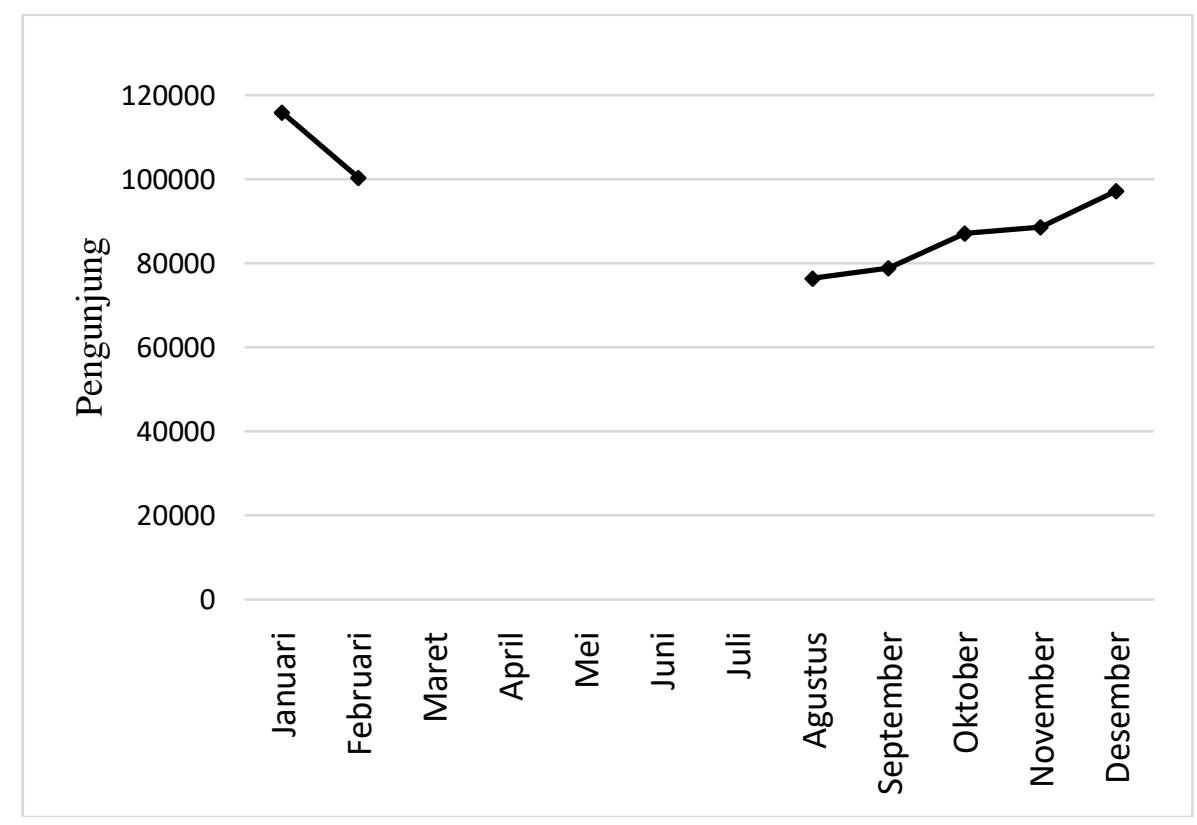

Gambar 3. Prediksi Pengunjung Taman Wisata Selecta Tahun 2020.

Pada Bulan Januari-Februari, jumlah pengunjung taman rerkeasi Selecta masih cenderung normal jika dibandingkan dengan waktu-waktu sebelumnya. Pada Bulan Maret, dilaksanakan kebijakan PSBB yang mengharuskan taman rekreasi selecta tutup sementara dari tanggal 16 Maret hingga 24 Juli 2020, sehingga observasi pada bulan-bulan tersebut tidak ditampilkan. Taman Rekreasi Selecta kembali buka normal selama satu bulan penuh di Bulan Agustus 2020. Dari Bulan Agustus sampai dengan Desember 2020, jumlah 
pengunjung mulai meningkat dengan jumlah pengunjung tertinggi berada di Bulan Desember 2020. Sayangnya, nilai prediksi ini belum dapat dibandingkan dengan data resmi dari BPS karena data jumlah pengunjung tempat wisata di tahun 2020 belum dipublikasikan saat penelitian ini selesai ditulis.

\section{KESIMPULAN}

Adanya pola yang sama pada jumlah pengunjung Selecta dan Indeks Google Trend sejak tahun 2012 hingga 2019 menunjukkan adanya potensi penggunaan IGT dalam memperbaiki model prediksi jumlah pengunjung. Model prediksi pengunjung Selecta yang didapatkan adalah ARIMA $(0,1,2)(1,0,0)[12]$ dan ARIMAX $(0,1,2)(1,0,0)$ [12].Penggunaan IGT pada model SARIMAX terbukti mampu memperbaiki model nowcasting dilihat dari nilai MAE dan MAPE yang lebih kecil. Hasil estimasi pengunjung Selecta tahun 2020 menggunakan model SARIMAX menunjukkan bahwa jumlah pengunjung Selecta di Tahun 2020 menurun drastis akibat pandemi Covid-19.

Kedepannya, dapat dieksplor lagi penggunaan big data lainnya sebagai variabel penjelas pada model prediksi runtun waktu, seperti: indeks mobilitas google, mobile phone data, dan data dari aplikasi travelling. Selain itu, dapat dilakukan prediksi jumlah pengunjung untuk seluruh tempat wisata di Kota Batu, sehingga dapat memberikan manfaat lebih bagi pemerintah Kota Batu selaku pengambil kebijakan.

\section{DAFTAR PUSTAKA}

Akbar, I. A., \& Kurniawan, R. (2020). Pemodelan Nowcasting Tingkat Pengangguran Terbuka Menggunakan Data Google Trends Dengan Metode Antlion Optimization-Support Vector Regression. Seminar Nasional Official Statistics 2019: Pengembangan Official Statistics dalam mendukung Implementasi SDG's (dits. 760-770). Jakarta: Politeknik Statistika STIS.

Antolini, F., \& Grassini, L. (2018). Foreign arrivals nowcasting in Italy with Google Trends data. Quality \& Quantity.

Anugrah Putra, r. A., \& Arini, S. (ga go letlha). Measuring the Economics of a Pandemic: How People Mobility depict Economics? An Evidence of People's Mobility Data towards Economic Activities.

Arunraj, N. S., Ahrens, D., \& Fernandes, M. (2016). Application of SARIMAX Model to Forecast Daily Sales in Food Retail Industry. International Journal of Operations Research and Information Systems, 1-21.

Badan Pusat Statistik. (2020). Analisis Big ata Ditengah Masa Adaptasi Kebiasaan Baru. Jakarta.

Badan Pusat Statistik. (2020). Tinjauan Big Data Terhadap Dampat Covid-19. Jakarta.

Baribura, M., Giannone, D., \& Reichlin, L. (2010). Nowcasting. Working Pa per Serie s.

BPS Kota Batu. (2020). Gogilwe go tswa Badan Pusat Statistik Kota Batu: https://batukota.bps.go.id/subject/16/pariwisata.html

Eurostat. (2015). Glossary:In-sample vs. out-of-sample forecasts. Eurostat - Statistics Explained: https://ec.europa.eu/eurostat/statistics-explained/index.php?title=Glossary:In-sample_vs._out-ofsample_forecasts

Fasulo, A., Guandalini, A., \& Terribili, M. D. (2017). Google Trends for Nowcasting Quarterly Household Consumption Expenditure. Rivista Italiana di Economia Demografia e Statistica.

Fransiska, H., Novianti, P., \& Agustina, D. (2019). PERMODELAN CURAH HUJAN BULANAN DI KOTA BENGKULU. Seminar Nasional Official Statistics 2019: Pengembangan Official Statistics dalam Mendukung Implementasi SDG's, (dits. 390-395).

Hanas, I., \& Sasmita, N. (2014). Mengembangkan Pariwisata Membangun Kota: Kota Batu, 2001-2012. Artikel Ilmiah Mahasiswa.

Moritz, S., \& Bartz-Beielstein, T. (2017). imputeTS: Time Series Missing Value Imputation in R. R Journal.

Setyobudi, I. L. (2017). Peramalan Jumlah Pengunjung Taman Rekreasi Selecta dengan Metode Arima BoxJnkins. Tugas Akhir Institut Teknologi Sepuluh November. 